
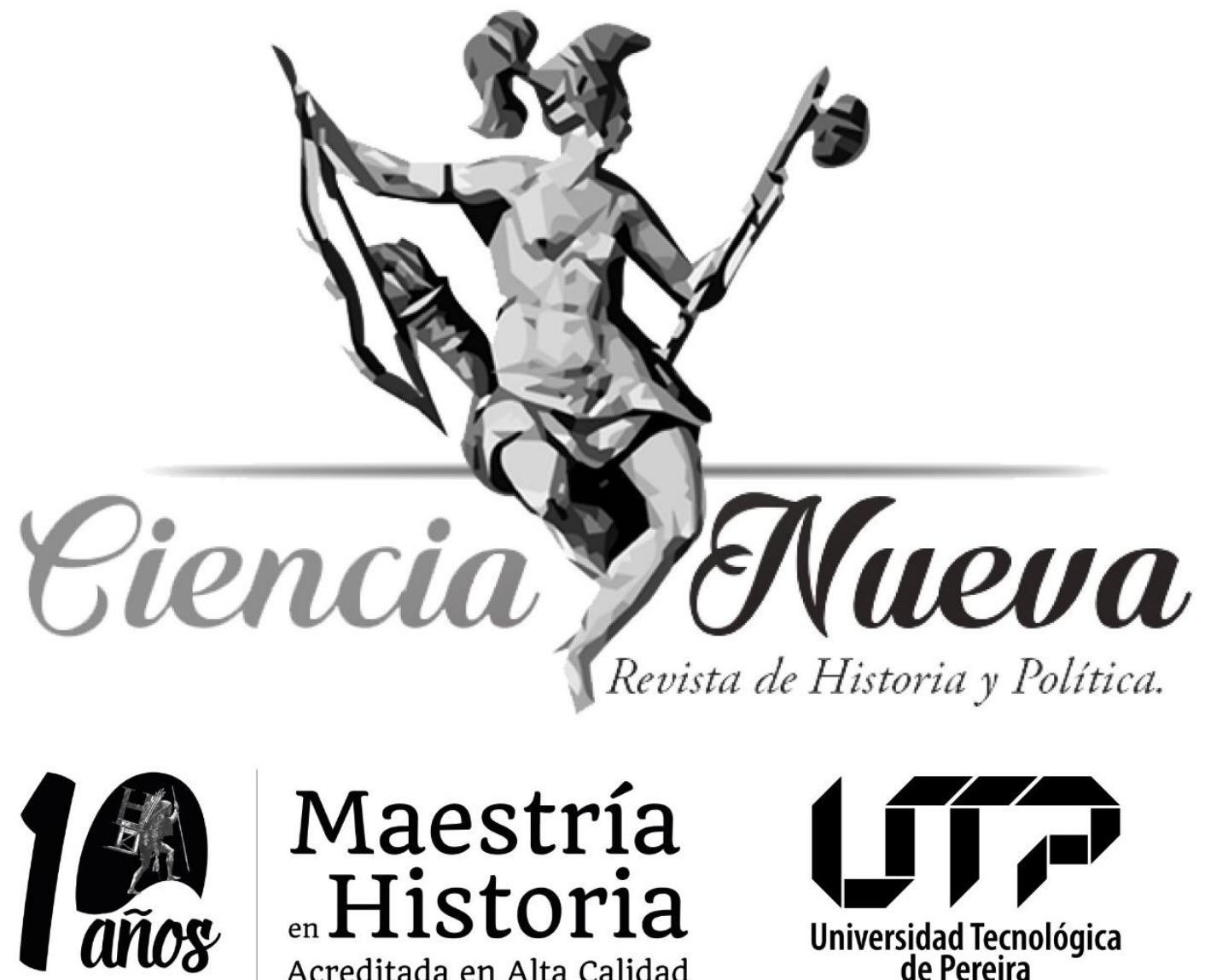

Maestría enHistoria

Acreditada en Alta Calidad

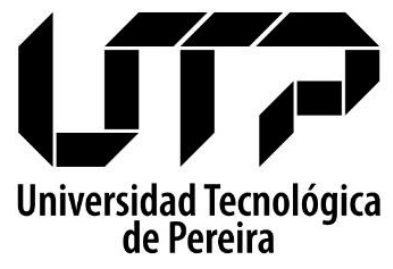

DOSSIER

DOS GUERRAS, ENEMIGOS DISTINTOS Y LAS MISMAS VÍCTIMAS. O CUANDO EL BICENTENARIO SILENCIA LA POSGUERRA TWO WARS, DIFFERENT ENEMIES, AND THE SAME VICTIMS. OR WHEN THE BICENTENNIAL SILENCES THE POSTWAR PERIOD José Ramos López pp. $150-173$

DOI: https://doi.org/10.22517/25392662.24041

Vol. 4 Núm. 2 | Julio-diciembre de 2020

Pereira, Colombia

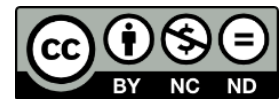




\title{
DOS GUERRAS, ENEMIGOS DISTINTOS Y LAS MISMAS VÍCTIMAS. O CUANDO EL BICENTENARIO SILENCIA LA POSGUERRA*
}

\author{
TWO WARS, DIFFERENT ENEMIES, AND THE SAME VICTIMS. OR WHEN THE BICENTENNIAL \\ SILENCES THE POSTWAR PERIOD
}

José Ramos López ${ }^{* *}$

runayraq@hotmail.com

ORCID: https://orcid.org/0000-0003-0785-1118

\begin{aligned} & \hline Recibido: 03 de abril de 2020. \\ & Revisado: 14 de septiembre de 2020. \\ & Aceptado: 03 de noviembre de 2020. \\ & Publicado: 31 de diciembre de 2020. \\ & \hline\end{aligned}

\section{Resumen}

La postergación de los derechos es una realidad que escinde al Perú y abre más las brechas de desigualdad entre los sujetos nacionales, a imagen de los grupos de poder, y los sujetos a quienes se les cuestiona su ciudadanía por no cumplir con los idearios nacionales. El presente artículo reflexiona sobre cómo la conmemoración del acto fundacional del Estado peruano enaltece los proyectos políticos de modernización y silencia la condición de sociedad de posguerra.

Palabras clave: sociedad de posguerra, bicentenario, sujetos nacionales, Estado nación.

\begin{abstract}
The postponement of rights is a reality that splits Peru and further opens the inequality gaps between the national subjects, in the image of power groups, and the subjects whose citizenship is questioned for not complying with national ideals. This article reflects on how the commemoration of the founding act of the Peruvian State exalts the political projects of modernization and silences the condition of a postwar society.
\end{abstract}

Keywords: postwar society, bicentennial, national subjects, nation-state.

\section{Introducción}

El sentimiento de pertenencia a una comunidad mayor, un «nosotros» diverso, cobra fuerza en encuentros deportivos con otros países, en especial con Chile; o en la rememoración de eventos históricos anclados en fechas del calendario patrio festivo. La mayoría de esas fechas está compuesta por la culminación de un hecho social, como guerras externas; actos de entrega (heroísmo) por la defensa de la patria, en los que el cuerpo masculino es representado pomposamente, y acuerdos diplomáticos fundacionales. Aquellas fechas que condensan eventos dignos de recordar nuestro Estado nación han sido objeto de una selección histórica bajo la lógica de enaltecer los proyectos políticos de construcción del ideario

\footnotetext{
* Este documento respeta las directrices y normas dispuestas en la Declaración de Ética de Publicación de Ciencia Nueva, Revista de Historia y Política. Esta declaración puede consultarse en la página web de la revista: http://revistas.utp.edu.co/index.php/historia

* *Antropólogo egresado de la Universidad Nacional de San Cristóbal de Huamanga (Perú), activista de derechos humanos y perteneciente a la etnia quechua.
} 
nacional, y silencian aquellas que resultaban una amenaza a la formación y consolidación del discurso de la nación peruana. En consecuencia, produce una diferenciación entre fechas indignas a un recuerdo y fechas dignas, que el Estado peruano promueve mediante «ceremonias patrióticas» expresadas en desfiles y feriados (días de descanso).

Las fechas patrióticas engloban una suerte de doble propósito: por un lado, el deber de recordar y rendir tributo al evento histórico a través del ritual militar (desfile) y, por otro, recompensar a la persona no solo por el sentimiento patriótico, sino por ser ciudadano perteneciente a una institución pública, sea en condición de servidor del Estado o individuo en formación para los fines del Estado (ser ciudadano). Las que son vividas de distintas formas: para un estudiante representa la materialización de los valores patrióticos que debe seguir; para un funcionario del Estado es un día de descanso por su servicio; para un campesino es una ocasión para reafirmar su patriotismo, reconocimiento de su ciudadanía cuestionado históricamente por la élite letrada; para un nativo amazónico viene a constituir el festejo de su dominación, la pérdida de autonomía local y el irremediable ingreso al Estado nación para ser considerado como «miembro de la patria» y dejar aquel ropaje estigmatizante impuesto violentamente: salvaje.

En esa línea argumentativa, hay una fecha emblemática, oficializada y rimbombantemente celebrada, que remonta a la proclamación de la independencia del Perú: el 28 de julio de 1821, hecho fundacional de la república peruana. Aquella frase representativa, considerada como la partera de la historia republicana como un Estado nación: «el Perú es, desde este momento, libre e independiente por la voluntad general de los pueblos y por la justicia de su causa que Dios defiende», palabras emitidas por José de San Martín en la plaza de armas de Lima, que agrupan aspectos principales del ideario nacional, como libertad, soberanía fundacional, apuesta por el proyecto político de «peruanos conscientes», ordenamiento más equitativo que en la colonia y la creencia heredada de España. El día de la independencia ha sido y es un hito histórico fundacional, que no solo es la reiteración de rituales enmarcados dentro de la celebración de fiestas patrias, sino más bien que articula distintos sentidos de vivir en condición de ciudadanos de un Estado. Marca un punto de referencia histórico entre el pasado vivido y el presente, para materializar los idearios nacionales en el futuro. Es decir, un día, el 28 de julio ha pasado a la historia como aquella fecha que condensa todo el proceso de la independencia tanto en sus actos, prácticas, discursos y referentes simbólicos como en ese pasado indisputado, traído al presente para dotarle de significados festivos. Además, en cada acto conmemorativo se han agregado, omitido, reactualizado y transformado otros sentidos de significación acorde al contexto sociopolítico. Es una forma de condensar un proceso en momentos específicos para su rememoración, que llamamos «metafechas de la independencia».

A la par, tras el transcurrir de los años, se ha materializado a los «padres fundadores de la patria» y las gestas heroicas de personajes que defendieron el destino de la nación en construcciones arquitectónicas, monumentos y estatuas con miras a infundir los valores patrióticos. Y el anclaje de estos hechos corresponde al centenario (1921), al sesquicentenario (1971) y, actualmente, al bicentenario (2021), acompañado de una política basada en el balance del proyecto civilizador-modernizador del Estado en materia de ciudadanía y servicios para alcanzar el futuro deseado. En ese sentido, en qué marco sociopolítico se inscribe el balance de las fechas destinadas a repensar la nación, las que están sujetas a un ejercicio de selección haciendo más visible, destacable, privilegiado algunos procesos históricos, y silenciando, relegando o simplificando las que se sitúan fuera del marco establecido por el Estado nación. Este interrogante es la guía a lo largo del trabajo para 
examinar cómo la condición de sociedad de posguerra se ha invisibilizado en el proyecto celebratorio de metafechas de la independencia.

Metodológicamente, esta investigación delimitó dos acontecimientos de guerra desarrollados a finales del siglo XIX y XX, la guerra del Pacífico y el conflicto armado interno, respectivamente; próximos a las metafechas de la independencia y las que han configurado políticas de modernización para construir sujetos nacionales. Se enmarca en la propuesta teórico-metodológica de Fernand Braudel ${ }^{1}$, situar estos acontecimientos en periodos de larga duración que permitan ver las regularidades, las maneras en cómo se gestaron determinadas formas de organizar los acontecimientos y darles significación. Se utilizó la hermenéutica para la recopilación de datos, consultando principalmente el Centro de Documentación e Investigación del Lugar de la Memoria, la Tolerancia e Inclusión Social (LUM).

Como componente de análisis de las «metafechas de la independencia», resaltamos la categoría de sociedad de posguerra por cuatro razones: primero, por ser una realidad presente que ha calado en nuestra historia republicana reciente, siendo la guerra del Pacífico (1879-1883) y el conflicto armado interno (1980-2000) escenarios cruentos; segundo, tanto la guerra externa e interna ha generado un ambiente de discusión para repensar el Perú como nación en busca de problemas y culpables, los indios/campesinos/indígenas en ambos; tercero, la continuidad de dinámicas violentas producidas por el conflicto ha permeado la reconstrucción del tejido social, la reconciliación y la justicia, y cuarto, la condición de Perú como sociedad de posguerra ha sido el contexto donde se celebraron las metafechas de la independencia como momento histórico, sin haber sido incorporadas.

El presente escrito versa del silenciamiento por enaltecer el pasado histórico y eliminar cualquier componente riesgoso que cuestione la idealización del pasado republicano o que escinda, más de lo que está, al Perú. Para ello, en la primera sección se explica la utilidad de la posguerra como elemento para repensar las metafechas de la independencia. La segunda parte aborda el establecimiento excluyente del Estado nación a imagen de los grupos de poder criollo que moldearon la idea del sujeto nacional. El tercer y cuarto apartado muestran la trama negacionista de asumir la posguerra en la conmemoración de las metafechas de la independencia a fin de mantener la grandilocuencia del proyecto de modernización. Finalmente se brindan algunas reflexiones.

Si bien, dentro de la literatura historiográfica existen discusiones respecto a dónde inicia la historia republicana, siendo para algunos desde la conformación del primer Congreso Constituyente (1821) y para otros desde el proceso de emancipación. Estudios centrados en las polémicas entre republicanos y monárquicos, en la naturaleza del proyecto político de la república, en resumidas cuentas, si fue concedida, concebida o conseguida o en la participación de los pueblos indígenas dentro de la república. Sería un esfuerzo agotador enumerar las múltiples investigaciones sobre la historia republicana, pero podemos encontrar dos formas de análisis: la primera parte de los estudios centran la mirada en hechos fundacionales, elitista, y el otro bloque hace un recorrido a las trayectorias políticas de sectores marginados por la historia oficializada, su agencia dentro del proceso de independización y la participación ciudadana en la república. En ese sentido, nuestro tinte reflexivo se enmarca en una aproximación de pensar el bicentenario desde la posguerra, puesto que la postergación de esta condición social puede introducirnos a ver lo silenciado. Consideramos importante problematizar este aspecto, ya que nos permitirá no solo conocer

${ }^{1}$ F. Braudel, La larga duración en la historia y las ciencias sociales (Madrid: Alianza, 1979). 
los sucesos, sino develar el trasfondo de la trama negacionista por los grupos de poder y la proliferación de discursos de odio para construir un colectivo racista, discriminador en aras de seguir con el progreso/desarrollo.

\section{La posguerra como elemento para repensar el Estado nación en el bicentenario}

Al menos las tres décadas del siglo XXI, la conmemoración de doscientos años de independencia del yugo español y nacimiento de Estados nación modernos en América del Sur será una oportunidad de transformar los sentidos de la historia plural y repensar cómo se están construyendo sujetos nacionales en cada país. Pues resulta ser un gran reto para las distintas colectividades responder a las exigencias del momento histórico y voltear la mirada a las prácticas sociales «normalizadas» como la corrupción, la discriminación, la violencia en todas sus expresiones y materializaciones. Ya estamos con pasos adentro del momento para evocar un proceso compartido: la «era de la conmemoración» ${ }^{2}$. La mayoría de los países ya experimentaron la celebración central de manera consecutiva, circunscrita a la «metafecha de la independencia», tales como: Bolivia y Ecuador, el 2009; seguido por Venezuela, Argentina, Colombia, México y Chile, el 2010; en el 2011, Uruguay, Paraguay y El Salvador. En nuestro país, Perú, tendrá lugar en el 2021, lo que significa una cierta comprensión de las experiencias conmemorativas en otras naciones que puedan sugerir puntos de quiebre en la conmemoración reflexiva, polivocal, participativa y horizontal.

En los países que ya han celebrado, los discursos, prácticas y las representaciones del uso de la historia para la conmemoración han sido proyectos desprovistos de un componente crítico sobre lo que significa mantener los Estados nación de hoy ${ }^{3}$. Al contrario, han afianzado celebraciones espectaculares y monumentales, pero con carácter efímero ${ }^{4}$, que exaltan los ideales nacionales decimonónicos 5 , la historia patria, héroes y batallas ${ }^{6}$, legitimando la forma de obrar del Estado ${ }^{7}$. El peso de la historia ha sido traducido en generar políticas públicas de bienestar y orden, mostrando Estados sólidos, desarrollados y orgullosos de su pasado ${ }^{8}$, con la inversión de recursos monetarios y humanos para revestir los lugares, espacios y personas del sentimiento de patria, mediante mecanismos de memoria, como la

\footnotetext{
${ }^{2}$ P. Nora, Les Lieux de memoire (Montevideo: Trilce, 2008), 167.

${ }^{3}$ Con excepción de algunas iniciativas alternativas que escaparon del uso público de la historia propuesta por los proyectos conmemorativos, pero que estuvieron marcados por el desprestigio por parte del Estado. El ejemplo más claro lo podemos ver en Colombia, en donde las exposiciones del Museo Nacional, «Las historias de un grito. 200 años de ser colombianos», fueron espacios planteados para la reflexión crítica alejándose de las pretensiones de narrar la historia de manera lineal y elitista; lo que desató una discusión respecto a cómo recordar el pasado. Para la comprensión de los contenidos puede revisar M. V. de Robayo, O. I. Acosta y A. Santamaría, Las historias de un grito: doscientos años de ser colombianos. Exposición conmemorativa del bicentenario (Bogotá: Museo Nacional de Colombia, 2010). Para la discusión véase E. Jelin, Las conmemoraciones: Las disputas en las fechas «in-felices» (Madrid y Buenos Aires: Siglo XXI Editores, 2002) y S. Vargas, «200 años de construir colombianos». Memoria y Sociedad 14, n. ${ }^{\circ} 29$ (2010): 147-150.

${ }^{4} \mathrm{~S}$. Vargas, «El bicentenario de la independencia en Colombia: rituales, documentos, reflexiones», Memoria y Sociedad 15, n. 31 (2011): 67.

${ }^{5}$ D. Hernández, «Actos de la nación. Conmemoración, identidad y representación: análisis del Bicentenario mexicano», Pacarina del Sur 8, n. ${ }^{\circ} 30$ (2017).

${ }^{6} \mathrm{~S}$. Vargas, «200 años de construir colombianos».

${ }^{7}$ D. Kersffeld, «Entre evocaciones y desmemorias: México ante su propio Bicentenario», en La revolución en el bicentenario. Reflexiones sobre la emancipación, clases y grupos subalternos, coord. por B. Rajland y M. C. Cotarelo (Buenos Aires: CLACSO, 2009), 115-131.

${ }^{8}$ J. Guerrero, L. Wiesner y F. Martínez (comps.), Memoria, historia y nación. A propósito del bicentenario de la independencia de Latinoamérica (Medellín: La Carreta Editores, 2010).
} 
construcción de obras públicas del bicentenario (obras viales y construcciones urbanas), conciertos masivos, exposiciones públicas, ferias, desfiles militares, encuentros académicos, publicaciones, entre otras.

Frente a los rituales oficializados por el Estado también hubo otras formas alternativas de sentir «los 200 años de independencia», que no necesariamente se ceñían al marco de celebración, sino al cuestionamiento de lo que significa el mantenimiento de dicho Estado a través de protestas de organizaciones sociales ${ }^{9}$. Como ya advertía Jelin, la importancia del establecimiento de las conmemoraciones rituales en fechas concretas genera un campo de batalla de distintas memorias para ser reconocidas ${ }^{10}$, y el bicentenario no fue ajeno a debates y disputas sobre las políticas de la memoria — sean oficiales o alternativas - entre diferentes actores sociales, políticos y académicos. De ello se desprende que el mandato de hacer memoria al nacimiento del Estado nación, no necesariamente es sentida como se plantea en los sujetos sociales integrantes de ella. Esto se hace mucho más notorio cuando no los representan los contenidos a recordar o los representa con énfasis a algún atributo, pudiendo ser lo salvaje, lo violento, lo autóctono, lo degenerado, lo victimizado, lo infantil, lo sentimental, lo inferior, lo abyecto, entre otros.

Obrar de esta forma hace más lejana la necesidad de honrar a los padres fundacionales de la nación. Es urgente comprender el costo de la mantención del Estado peruano que tenemos, aquel que posa su mirada en los países «neoliberales por excelencia»para transformar la realidad peruana en algo similar a ello, ignorando las urgencias sociales y políticas de los que se sienten vulnerados, violentados y no reconocidos plenamente por el Estado peruano. Pueblos nativos amazónicos, andinos y campesinos, arrinconados con las políticas extractivas de desarrollo y libre mercado. Mujeres, jóvenes, afroperuanos y personas TLGBI $^{11}$ experimentan a diario la vulneración de sus derechos por las precarias políticas públicas y las prácticas naturalizadas de estructuras de dominación, discriminación y estigmatización.

¿Cómo aproximarse al bicentenario sin correr el riesgo de quedar atrapados por la grandilocuencia del relato histórico oficializado? ¿Cómo el proyecto de modernización del Estado nación ha producido sujetos nacionales a imagen de los grupos de poder? ¿Cómo entender la continuidad de desigualdades y su legitimación en la conmemoración de las metafechas? La sociedad de posguerra, como categoría analítica, puede brindarnos algunas aproximaciones a las dinámicas de poder y la construcción del Estado nación moderna en nuestra historia republicana, en la que el modelo de sujeto nacional lo constituían criollos, urbanos, letrados-educados, comerciantes-emprendedores, es decir, los grupos de poder que, en «nombre del gobierno», tenían que transformar a sujetos construidos desde la diferencia del modelo civilizador impuesto. La opción de establecer una sociedad igualitaria, democrática, respetuosa de los derechos humanos y la diversidad cultural ha sido relegada, después de la culminación de guerras como momentos oportunos para fundar, en el caso de la guerra civil por la independencia (1824), reestructurar el Estado nación en la guerra del Pacífico (1983) y el conflicto armado interno (2000). Debemos comprender la sociedad de la

\footnotetext{
${ }^{9}$ R. Rueda, «El 20 de julio de 1810. Un episodio de protesta urbana en Bogotá», Memoria y Sociedad 11, n. ${ }^{\circ}$ 23 (2007). R. Vega, «Amargo bicentenario de la independencia en Colombia, ¿cuál independencia?», Casa de las Américas, n. ${ }^{\circ} 260$ (2010).

${ }^{10}$ E. Jelin, Las conmemoraciones...

11 Trans, lesbianas, gais, bisexuales e intersexuales.
} 
posguerra como la restitución de la paz, la cual «es la continuación de la guerra por otros medios» $^{12}$.

Más aún, Perú ha atravesado el centenario y experimentará el bicentenario en su condición de posguerra. Pero su actuar evidencia la postergación de los derechos, realidad que escinde al Perú y abre más las brechas de las desigualdades entre sujetos nacionales (los que se sienten representados) y sujetos a quienes se les cuestiona su ciudadanía (campesinos andinos, amazónicos, mujeres, afroperuanos, jóvenes y TLGBI). Centramos la mirada en cómo la condición de sociedad de posguerra más que asumir políticas de reconstrucción del tejido social ha significado la escisión del país que reniega de dicha condición y se esfuerza por superarla o «voltear la página» a fin de abrazar el desarrollo. Las élites políticas y culturales narraron los acontecimientos no centrándose en contar lo que pasó, sino en cómo contando lo que pasó podían establecer sus privilegios y normativizar la memoria en la que se enaltece los ideales del Estado nación. En los siguientes apartados reflexionamos sobre el desdén de desconfianza hacia las poblaciones andinas en la sociedad de la posguerra, contexto donde se sitúa el bicentenario.

\section{Una rápida mirada a la fundación del Estado nación}

Tras tres largos siglos de absoluta vigencia del proyecto de expansión del viejo continente, surgieron voces que anunciaban la libertad de los pueblos americanos, influenciados por las ideas liberales. Los gritos libertarios se materializaron en cruentas guerras civiles, haciendo posible la ruptura política de España con América tras la batalla de Ayacucho en 1824. El proceso de emancipación de las colonias españolas en América había culminado abruptamente dando paso a la conformación de Estados republicanos. La participación de indios en la guerra civil fue guiada por personalidades que encarnaban los intereses de la aristocracia criolla (grandes terratenientes, comerciantes y profesionales), que reclamaron sus privilegios de tutelar el destino de la patria por haber contribuido al nacimiento del Estado nación con su espada.

A su vez, el miedo de perder los privilegios adquiridos en la colonia incentivó a la apresurada creación del Estado, mediante el Congreso Constituyente en 1822, en el que solo 5 departamentos estaban ocupados por separatistas puesto que el resto era de dominio del ejército español. Tal como advierte Anderson en afirmar que una de las principales razones de la urgencia de la independencia «... era el temor a las movilizaciones políticas de la "clase baja", como los levantamientos de los indios o los esclavos negros» ${ }^{13}$. El discurso independista de las élites criollas tenía el propósito de alejar a los indios, esclavos y mujeres de la política, lo más posible que se pudiera porque constituía una amenaza al statu quo. Una frase representativa de Bolívar puede develarnos la mentalidad del siglo decimonónico: «... una rebelión negra era mil veces peor que una invasión española» ${ }^{14}$.

Si bien, San Martín, en la proclamación de 1821, decretó que «en lo futuro, los aborígenes no serán llamados indios ni nativos; son hijos y ciudadanos del Perú, y serán conocidos como peruanos» ${ }^{15}$, no lo aplicó en la práctica. Más aún cuando en 1825 Simón Bolívar abolió «el título y autoridad de los caciques» ${ }^{16}$ que poseían los pueblos indios. El

\footnotetext{
${ }^{12}$ H. Arendt, Sobre la violencia (Madrid: Alianza Editorial, 2005), 18.

${ }^{13}$ B. Anderson, Comunidades imaginadas. Reflexiones sobre el origen y la difusión del nacionalismo (México D. F.: Fondo de Cultura Económica, 1993), 78.

${ }^{14}$ Anderson, Comunidades imaginadas...,79.

${ }^{15}$ Lynch, 1973 en Anderson, Comunidades imaginadas...,276.

${ }^{16}$ M. Thurner, Republicanos andinos (Lima: IEP; CBC, 2006), 64.
} 
nuevo Estado nación se sostenía en las estructuras coloniales de dominación y explotación hacia colectividades ajenas a la ideología criolla, que proponía una ciudadanía exclusiva revestida de razón y legitimidad. Por citar, el derecho al voto de los indígenas analfabetos e inclusive a los que sabían leer y escribir - se negó con la Constitución de 1828; y reconocido a partir de 1856 con la Constitución de Ramón Castilla. Similarmente, la abolición de la esclavitud la proclamó en Huancayo en 1854 para engrosar sus filas y vencer a José Echenique. Castilla actuó más guiado por la presión social, que por una decisión consciente.

Entonces, dónde quedó la promesa de transformar la dominación colonial para ser un país libre e independiente con una ciudadanía para todos y todas. La posguerra de la independencia ha estado marcada por el uso de mecanismos para imaginar un Estado nación desde y para las élites sociales criollas, que pueda administrar la violencia ${ }^{17}$ hacia los grupos minoritarios a fin de transformarlos en sujetos dignos del Perú en construcción. Por ello, seguir perpetuando la dominación colonial, pero ahora revestida con el ropaje de «república democrática» mediante la consolidación de los idearios nacionales. En el Perú, la constitución del Estado nación tiene como base una matriz colonial que «glorifica la cultura incaica, pero reniega de la degradación de los indígenas» ${ }^{18}$, considerados por los criollos como hombres inferiores, infantiles y brutales. La élite criolla, bajo el pensamiento de la ilustración, funda el Estado peruano bajo el paradigma de la exclusión de los indígenas. Al analizar la génesis narrativa de la imaginación nacional caracterizada por una inscripción fracturada del pasado y presente, Mark Thurner concluye que «al "nosotros" criollo lo perseguía siempre el fantasma de un "ellos" indígena domésticamente distante y a veces amenazante, un compatriota subalterno condenado por la historia liberal a habitar la edad de oro prehistórica de la nación» ${ }^{19}$.

La pugna por el poder entre caudillos, militares y civiles era un péndulo conflictivo entre los liberales y conservadores que intentaban detentar el poder para gobernar la nación. En ese contexto, se impuso el nacionalismo criollo de raigambre elitista y autoritario marcado por el desprecio y segregación del indio. Lo que obedecía a las ideas decimonónicas del progreso (positivismo y biología), que ayudaron a consolidar una ideología de desprecio, «una "república sin indios" parecía ser el lema del progreso» ${ }^{20}$, a pesar de la participación masiva de campesinos en guerrillas de los caudillos como un mecanismo legítimo de política $^{21}$.

\section{¿El problema del indio o del Estado nación? y el centenario de la independencia}

Durante el cumplimiento del centenario de la independencia (1921), la sociedad peruana había experimentado una crisis política por las constantes guerras civiles entre caudillos, militares y civiles que iba lejos de consolidar una nación. Al cumplirse el primer

\footnotetext{
${ }^{17}$ Hannah Arendt tras criticar la simplicidad del abordaje de la violencia, confundiéndola con el poder, fuerza o autoridad, menciona que el «poder y la violencia son opuestos; donde uno domina absolutamente falta el otro. La violencia aparece donde el poder está en peligro, pero confiada a su propio impulso, acaba por hacer desaparecer al poder» Thurner, Republicanos andinos..., 72. De ello, concluye que la violencia es un instrumental utilizado por la clase dominante o en resistencia hasta alcanzar el fin que deba justificarla.

${ }^{18}$ C. Méndez, Incas sí, indios no: apuntes para el estudio del nacionalismo criollo en el Perú, $2^{\mathrm{a}}$ ed. (Lima: IEP) (n. ${ }^{\circ}$ 56, Serie Historia 10), 2000.

${ }^{19}$ M. Thurner, Republicanos andinos (Lima: IEP; CBC, 2006), 454.

${ }^{20}$ Méndez, Incas sí, indios no..., 27.

${ }^{21}$ C. Méndez, La república plebeya. Huanta y la formación del Estado peruano, 1820-1850 (Lima: IEP, 2014).
} 
centenario en el segundo gobierno de Augusto Leguía (1919-1930), Perú registró 96 presidentes con 18 golpes de Estado, realidad que demostraba la fragilidad política donde el afán de controlar la patria había hecho imposible conformar un sentimiento de pertenencia a la comunidad peruana. Lo que tendría costos muy fuertes en la guerra del Pacífico. Y, ¿los indígenas, los esclavos y las mujeres seguían siendo percibidos como infantiles sin capacidad de ejercer la ciudadanía (sujetos no nacionales)?

El auge económico del guano generó una pasajera estabilidad del país con la que se buscó principalmente: primero, acentuar el poder económico y político de Lima y de la costa con la emergencia de una burguesía criolla basada en la plutocracia; segundo, materializar el progreso del país mediante la construcción de líneas ferroviarias como un recurso de salvación y unión con otras regiones ${ }^{22}$; tercero, embellecer las ciudades con construcciones monumentales, por ejemplo, en Ayacucho se realizaron obras públicas, tales como la instalación de alumbrado público a gas en 1857, la construcción del paseo Alameda en 1862, la construcción del arco conmemorativo a la batalla de Ayacucho de 1824 (que culminó 11 años después), entre otras; cuarto, la emergencia de caudillos provinciales, «gamonales» ${ }^{23}$, que se beneficiaban por los ingresos del guano, y la naciente burguesía conformada por hacendados y comerciantes de carne y lana, quienes tuvieron un rol más activo en la política regional $^{24}$, y quinto, impulsar el proceso de nacionalización —asimilación, colonización y civilización - de la región selvática para potenciar la economía productiva nacional y convertir a los nativos amazónicos en personas que fueran útiles al Estado nación, en esa línea Núria Sala i Vila encuentra que la colonización de la selva estuvo guiado por el racismo y desprecio hacia los hombres que la habitaban ${ }^{25}$.

Por consiguiente, el boom guanero agravó las brechas existentes entre la costa modernizante y la sierra económicamente atrasada ${ }^{26}$. Pronto se haría sentir el descontento de la aristocracia provinciana frente a la oligarquía capitalina que monopolizaba las ganancias del guano. Reclamaban la descentralización, como el caso de la sublevación de Huanta contra el gobierno de Castilla en $1856^{27}$. Perú se encontraba profundamente escindido dándose cuenta de que mantener las estructuras de dominación hacia sujetos no dignos de la nueva

\footnotetext{
22 «... si en las naciones europeas el papel de un camino de hierro se reduce a facilitar y activar las comunicaciones entre dos puntos del territorio, en el Perú su misión es de crear esas relaciones que no existen entre lugares que están incomunicados unos de otros; en Europa ellos facilitan el tráfico y el comercio, fomentan así la industria y dan mayor valor a la propiedad; en el Perú lo creará todo: comercio, industria y hasta propiedad, porque darán valor a lo que hoy no tiene» H. Bonilla, Guano y Burguesía en el Perú (Lima: IEP, 1984$), 51$.

23 «Los "gamonales" o caciques provinciales eran los hombres fuertes que se erigían como mediadores entre el Estado y las sociedades provinciales. Podían ser hacendados, funcionarios públicos, comerciantes importantes, jefes militares o combinar estas condiciones. Eran una suerte de pequeños monarcas de provincia que controlaban la vida política y social de sus localidades, gracias a la red de clientes que conseguían y porque eran designados como subprefectos, jueces o alcaldes» A. Zapata, N. Pereyra y R. Rojas, Historia y cultura de Ayacucho (Lima: IEP, UNICEF, 2008), 137.

${ }^{24}$ P. del Pino, «Huamanga en la guerra con Chile. 1879-1884» (Informe de investigación para optar el grado de bachiller. Universidad Nacional San Cristóbal de Huamanga, Ayacucho, 1990), 16.

25 «Una vez conquistada la región para la agricultura y futuros colonos, se lograría que los indios "chunchos" se vieran obligados a "tratar, comerciar y familiarizar con nuestros montañeses" lo que a la postre los civilizaría». El Liberal, edición 40, noviembre de 1856, citado por N. Sala i Vila, Selva y Andes. Ayacucho (1780-1929). Historia de una región en la encrucijada (Madrid: Consejo Superior de Investigaciones Científicas, 2001), 44.

${ }^{26}$ P. Klaren, Nación y sociedad en la historia del Perú (Lima: IEP, 2005), 211.

${ }^{27}$ P. Husson, De la guerra a la rebelión. (Huanta, siglo XIX) (Lima: Instituto Francés de Estudios Andinos, 1992), 160.
} 
república tendría un costo muy alto en la guerra con Chile. Intentar alejar a los indios de la política supuso restringir la posibilidad de que pudieran ilustrarse y civilizarse gradualmente, de modo que pudieran unirse al resto de ciudadanos. La ciudadanía exclusiva para los criollos se permeó con la declaración del sufragio universal para mestizos e indígenas — sin incluir a las mujeres - decretado por Ramón Castilla en 1856. Lejos de reflejarse en la práctica, el nacionalismo criollo constituyó la «definición de lo "nacional-peruano" a partir de la exclusión y desprecio del indio» ${ }^{28}$.

Cecilia Méndez, al analizar el proyecto político del nacionalismo criollo por abolir la confederación Perú-Boliviana (1836-1839), encuentra el sustrato ideológico de la élite criolla - y los mestizos que se identificaban o aspiraban serlo- en los escritos de Felipe Pardo sobre los indios. El «indio es, pues, aceptado en tanto paisaje y gloria lejana. Es "sabio" si es pasado y abstracto, como Manco Cápac. Es bruto o "estoico", e "impuro" y "vándalo", si es presente, como Santa Cruz» ${ }^{29}$. Según la ideología de los criollos, la condición étnica de Santa Cruz provista de la razón y la insaciable búsqueda de poder era un peligro para el futuro de la nación por lo que debía «regresar a su lugar».

Con mayor fuerza, la aristocracia criolla en la guerra del Pacífico hace un llamado para que los indígenas demuestren su patriotismo a fin de defender la nación a la que pertenecen. Luego de prácticas de exclusión hacia los pueblos indígenas se les convocaba para que demostraran su poderío «violento» y para que lucharan contra el ejército chileno. Los campesinos ejercieron un cierto nivel de ciudadanía por las armas en las guerras civiles para la formación del Estado peruano ${ }^{30}$, como también al integrar las milicias de los caudillos en la república temprana como un estado de excepción donde se les permitía ingresar hasta cierto punto, hasta que se restableciera el orden requerido por la élite criolla. Tal como precisa Remy (1991), siguiendo a Girard, la violencia «producida y controlada socialmente a través de prácticas ritualizadas es un método preventivo que protege al grupo del estallido de una propia violencia ${ }^{31}$. Evidencia una administración eficiente de la violencia basado en las razones compartidas por un colectivo criollo, tanto la levedad como la gravedad son vistos como un mal empleo de la violencia.

En ese marco comprensivo, la guerra para los indígenas era un problema lejano y en cierta medida ajeno. Esto responde a que el proyecto de Estado nación del Perú estaba muy centrado en la mantención de privilegios a los criollos y el sometimiento de pueblos indígenas, generando un escenario marcado por rivalidades no solo entre criollos e indígenas, sino criollos capitalinos, comerciantes y gamonales provincianos. Lo que hacía mucho más complejo el sentido de pertenencia a un Estado nación desigualitario donde la ciudadanía estaba reservada para criollos. En cambio, Chile venía convirtiendo a sus habitantes en sujetos nacionales con una identidad política y cultural mediante el proyecto de Estado nación desde 1830. Por ejemplo:

\footnotetext{
${ }^{28}$ Méndez, Incas sí, indios no..., 15.

${ }^{29}$ Méndez, Incas sí, indios no..., 19.

${ }^{30}$ C. Méndez, «Tradiciones liberales en los Andes o la ciudadanía por las armas: campesinos y militares en la formación del Estado peruano», en La mirada esquiva. reflexiones históricas sobre la interacción del Estado y la ciudadanía en los Andes (Bolivia, Ecuador y Perú), ed. por M. Irurozqui (Madrid: Consejo Superior de Investigaciones Científicas, 2005), 125-153.

${ }^{31}$ M. I. Remy, «Los discursos sobre la violencia en los Andes. Algunas reflexiones a propósito de chiaraje», en Poder y violencia en los Andes, ed. por E. Urbano y M. Lawer (Cusco: Centro de Estudios Regionales Andinos Bartolomé de las Casas, 1991), 270.
} 
... para los ayacuchanos la guerra era un problema lejano. Sólo decidieron enviar batallones ( «dos de mayo», «9 de diciembre», «21 de diciembre», «Cazadores de la muerte» y «libres de Huanta») a la capital entre 1879 y 1881 con más de mil efectivos, más un poco de dinero que pudo ser recogido por las municipalidades de Huamanga y Huanta ${ }^{32}$.

Fue algo visible cuando el ejército chileno empezó a ocupar territorio peruano, destrozando gran parte de las haciendas costeras que eran la base de la economía nacional y la riqueza de la oligarquía. El 1 de octubre de 1883, los chilenos ingresaron a Ayacucho sin encontrar ninguna resistencia, puesto que una gran mayoría optó por la huída o el repliegue hacia el campo. La resistencia comandada por Andrés Avelino Cáceres en los Andes ocasionó un ambiente de polarización en la sociedad ayacuchana, siendo los campesinos de Huanta y Huancavelica los que conbatieron contra los chilenos, en alianza con hacendados procaceristas. Lo que años más tarde posibilitó su participación en la vida política y el acceso garantizado a recursos agrícolas. En cambio en Huamanga, los campesinos prefirieron mantenerse al margen de la guerra, por los constantes enfrentamientos con los terratenientes que imposibilitó el establecimiento de alianzas. Muchos campesinos desobedecieron los mandatos de «convertirse en soldados de la nación».

La misma forma de sentir la guerra era una clara muestra de la distancia existente: la aristocracia criolla al mando de tropas formadas por indios, mestizos y negros mal alimentados, con indumentaria insuficiente y obligados a defender una causa percibida como lejana de sus intereses inmediatos. La misma forma de concebir a los campesinos como «seres violentos y salvajes» tuvo sus costos, puesto que su actuar en la guerra distaba mucho del sentido de las hostilidades, siendo los criollos quienes encarnaban la agresión ${ }^{33}$. Bonilla, citando a Gonzalo Bulner, resalta un pasaje anecdótico ocurrido en la visita de Patricio Lynch junto al almirante francés Du Petit Thouars a uno de los hospitales limeños, allí realizó una pregunta sencilla a soldados de ambos bandos a fin de explicar al francés las razones de la derrota peruana ${ }^{34}$. Al preguntar el por qué de su participación en la guerra a dos peruanos, el primero le dijo: «Yo por don Nicolás [de Piérola]. Y el otro, por don Miguel [Iglesias]». Similarmente, formuló la pregunta a dos chilenos que respondieron al unísono: «iPor mi patria, mi general!». Lynch dirigiéndose a Thouars aceberó: «Por eso hemos vencido. Unos se batían por su patria, los otros por don fulano de tal». Efectivamente, en el Perú, el llamado a defender a la patria (Estado nación) respondía a un interés de defender los intereses del caudillo y de los hacendados que, para un eficiente control del Estado y sus privilegios, lograron tener su propio ejército conformado por milicias. En cambio, la élite chilena supo utilizar eficientemente los aparatos ideológicos del Estado para nacionalizar a sus habitantes, en palabras de Althusser, mediante la educación, el servicio militar obligatorio y la religión católica $^{35}$.

Para los campesinos era una oportunidad coyuntural de aprovechar para reclamar su adscripción al Estado, mostrando su nacionalismo popular. Aunque Bonilla asevera que los

\footnotetext{
${ }^{32}$ A. Zapata, N. Pereyra y R. Rojas, Historia y cultura de Ayacucho, 138.

${ }^{33}$ Del Pino, «Huamanga en la guerra con Chile. 1879-1884».

${ }^{34} \mathrm{H}$. Bonilla, El futuro del pasado. Las coordenadas de la configuración de los Andes, tomo II (Lima: Fondo Editorial del Pedagógico de San Marcos, 2005), 653.

${ }^{35}$ L. Althusser, «Ideología y aparatos ideológicos del Estado», en Ideología, un mapa de la cuestión, S. Zizek (México: Fondo Cultura Económica, 2008), 115-167. Carmen Mc Evoy encuentra que «apelar a Dios ha servido para legitimar la brutalidad que una guerra desata y para despertar la adhesión incondicional de los combatientes». Carmen Mc Evoy, «De la mano con Dios. El nacionalismo católico y la guerra del Pacífico, 1879-1881», 84 .
} 
campesinos no tenían la capacidad de pensar en nación, sino que su participación estaba guiada por vengar antiguos odios étnicos sin diferenciar chilenos de peruanos ${ }^{36}$. En la misma linea, Klaren menciona que «los campesinos que no tenían ninguna concepción de Estado nación no lograron comprender quién era el enemigo invasor (malentendido como el "general Chile") y, por tanto, en su confusión, no podían expresar una visión patriótica o nacionalista ${ }^{37}$. La postura pesimista del desenlace de la guerra expresada por la historiografía dependentistas fue refutada por Nelson Manrique, quién mediante un enfoque regional y el trabajo de archivo demostró la existencia de campesinos nacionalistas en la sierra central, que constituyeron alianzas multiclasistas para enfrentar la guerra con Chile ${ }^{38}$. $\mathrm{Su}$ trabajo concibe a los campesinos como seres políticos, alejándose de los estudios históricos de su época que imaginaban a los campesinos como «prepolítico», situada en la visión progresiva y lineal de la historia.

El periodo de reconstrucción nacional (1884-1895) estuvo marcado por la recomposición del sistema de haciendas, constituyentes de la economía nacional, y porque el campesinado volvió a ser objeto de sometimiento. Muchas de las promesas por su participación en la guerra les fueron negadas. Manrique relata que después de la guerra del Pacífico muchos campesinos indígenas sirvieron como soldados patriotas, y una vez desmovilizados se les negaron sus derechos ciudadanos a los hombres y las mujeres que consideraban indios peligrosos $^{39}$. Tal como señala Thurner, la idea de unidad nacional ha sido un uso efímero por los grupos criollos, ya que «asumir una postura nacionalista en la guerra con chile y en su culminación las aspiraciones campesinas fueron reprimidas por la élite peruana como demandas retrógradas y como furia irracional de las «hordas salvajes» ${ }^{40}$. Aunque, los campesinos podían ingresar y salir del Estado nación cuando la ocasión lo ameritaba, sin necesariamente estar excluidos de la vida nacional. Sin embargo, el discurso del proyecto nacionalista criollo — y con mayor fuerza en la posguerra - había reforzado las definiciones negativas sobre los campesinos como el principal problema por el que se había perdido la guerra. La aristocracia criolla renegaba por tener una población gruesa y mayoritaria por civilizar, educar y enseñar a ser miembros del Estado nación. Los intentos habían sido muy vacuos por transformar a la población indígena en sujetos nacionales mediante el progreso y la educación. Más bien, estuvo dominado por el manto racista y de desprecio que postergó la accesibilidad a la educación.

Es así como, en el siglo decimonónico, la nación estuvo marcada por la élite criolla que imaginaba a la diversidad de grupos étnicos del Perú y controlaba su acceso al poder por temor a perder su poder. Para Anderson:

La nación es una comunidad política imaginada como inherentemente limitada y soberana. Es imaginada porque aun los miembros de la nación más pequeña no conocerán jamás a la mayoría de

\footnotetext{
${ }^{36}$ H. Bonilla, «El problema nacional y colonial del Perú en el contexto de la Guerra del Pacífico», en Un siglo a la deriva, H. Bonilla (Lima: IEP, 1980). «Para los indígenas del Perú esta era una guerra de blancos, y que "el general Chile" y el "general Perú" no tenía mucho que ver con sus experiencias cotidianas» H. Bonilla, El futuro del pasado..., 605.

${ }^{37}$ P. Klaren, Nación y sociedad..., 243.

${ }^{38}$ N. Manrique, Las guerrillas indígenas en la guerra con Chile: campesinado y nación (Lima: Centro de Investigación y Capacitación, 1981).

${ }^{39}$ Manrique, Las guerrillas indígenas en la guerra con Chile.

40 Thurner, Republicanos andinos, 55.
} 
sus compatriotas, no los verán ni oirán siquiera hablar de ellos, pero en la mente cada uno vive la imagen de su comunión ${ }^{41}$.

El discurso racista, el desprecio por los indígenas, ha desempeñado un papel importante para producir sujetos que sirvan a la nación. Pues, «el nacionalismo oficial fue típicamente una respuesta de grupos dinásticos y aristocráticos -clases altas-amenazados por el nacionalismo vernáculo popular» ${ }^{42}$. Su inscripción violenta al proyecto civilizador a través de las instituciones como el servicio militar obligatorio, el tributo y la educación. Por su parte, Cecilia Méndez expresa que «los campesinos andinos constituyeron la columna vertebral de los ejércitos caudillistas del siglo XIX y fueron la principal fuente de reclutas a lo largo del xx. Asimismo, es en los poblados rurales donde los militares de un ejército más moderno han sido destacados innumerables veces a servir» ${ }^{43}$.

Los intelectuales del centenario como Manuel Gonzáles Prada, Raúl Porras Barrenechea, Jorge Basadre, Víctor Raúl Haya de la Torre y José Carlos Mariátegui reflexionaron sobre las tareas pendientes del Perú para construir un nacionalismo en la que la guerra con Chile era un punto clave de sus motivaciones. Muchas de sus reflexiones estuvieron marcadas por una suerte de crítica pesimista. Sus propuestas estaban enmarcadas en cambiar el orden injusto institucionalizado mediante una refundación de la república basada en la justicia para articular a la nación y a sus miembros transformarlos en sujetos nacionales. Las poblaciones indígenas, situadas en los Andes, eran vistas con buenos ojos civilizadores para integrarles a la nación a fin de que no constituían un problema de «carga» o de tutela. Gonzáles Prada refiriéndose a la supuesta amenaza de los indios construida por los criollos, advierte:

Felizmente, el Perú no se reduce a la costra corrompida y corruptora: lejos de políticos y logreros, de malos y maleadores, dormita una multitud sana y vigorosa, una especie de campo virgen que aguarda la buena labor y la buena semilla. Riamos de los desalentados sociólogos que nos quieren abrumar con sus decadencias y sus razas inferiores [...]. ¡Decadencia! [...] Aquí tenemos por base nacional una masa de indios ignorantes, de casi primitivos que hasta hoy recibieron por únicos elementos de cultura las revoluciones, el alcohol y el fanatismo. Al pensarles en decadencia, se confunde la niñez con la caducidad, tomando por viejo paralítico al muchacho que todavía no aprendió el uso de sus miembros ${ }^{44}$.

De manera similar, José Carlos Mariátegui asume una postura crítica sobre la idealización del indio, puesto que la literatura existente estaba lejos de dar una «versión verista del indio» ${ }^{45}$, más bien la idealizaba. Insiste en incluir a las poblaciones indígenas para liberar a la nación de la herencia colonial, solo pensando en un proyecto de nación heterogénea con una posición socialista se podría cambiar el rumbo del Perú. Mariátegui en Lo nacional y exótico, publicado en 1924, mencionó que el nacionalismo peruano no ha sido un proyecto real, sino solo para unos cuantos, los de tendencia conservadora; «el nacionalismo a ultranza

\footnotetext{
${ }^{41}$ Anderson, Comunidades imaginadas..., 23.

42 Anderson, Comunidades imaginadas..., 211.

43 C. Méndez, «Militares Populistas. Ejército, etnicidad y ciudadanía en el Perú», en Repensando la subalternidad. Miradas críticas desde/sobre América Latina, comp. por P. Sandoval (Lima: IEP, SEPHIS, 2009), 562.

${ }^{44}$ M. González, Horas de lucha (Lima, 1972), 21.

45 J. C. Mariátegui, Siete ensayos de interpretación de la realidad peruana (Lima: Biblioteca Amauta, 1995), 242.
} 
es la única idea efectivamente exótica y forastera que aquí se propugna» ${ }^{46}$. Por tanto, era necesario «peruanizar al Perú» desde la educación porque «ser letrado» era una abertura hacia la reflexión y la razón. En conclusión, las élites políticas y culturales en la posguerra se rebatían entre el «problema del indio degradado» o del Estado. Se criticaba la persistencia de la herencia colonial y la marginación de indios considerados fuera de la nación en el siglo decimonónico, la que debía ser urgentemente solucionada con las instituciones de progreso y desarrollo.

El centenario de la independencia se celebró en el conocido «oncenio de Leguía». Él había ganado las elecciones en 1919, bajo el lema de «patriotismo, talento y energía», y en nombre de «la nueva patria» inició un conjunto de obras públicas que pudieran modernizar al Perú en lo político, económico y social, posible con su lógica de «sin empréstitos no hay desarrollo». Las celebraciones empezaron el 27 de julio con la inauguración del monumento a San Martín y la plaza que lleva su nombre, estatua regalada por Argentina. El 28 de julio se recibió a 16 embajadas y 13 misiones especiales de distintas partes de Lima, a quiénes se les entregó la «medalla conmemorativa del primer Centenario de la Independencia Nacional», seguido de ceremonias festivas y banquetes. La noche fue seguida con la iluminación de los principales edificios de Lima, como la Casa de Correos, el Palacio de Gobierno, el Palacio Legislativo, la Plaza de Armas, la Plaza de San Martín y el Paseo de Colón. Basadre relata:

Diversas colonias extranjeras hicieron obsequios, solemnemente recibidos a veces en forma simbólica. El de la alemana fue una torre reloj para erigirla en el Parque Universitario; el de la española, un arco de triunfo para levantarlo en la avenida Wilson, a la entrada de ella, en la plaza Jorge Chávez; el de la británica, un estadio sito en el campo deportivo de Santa Beatriz. Quedaron postergados los actos concernientes a los obsequios de otras colonias: un palacete museo donado por la italiana hallábase en construcción; la colonia estadounidense se proponía entregar un monumento a Washington, bibliotecas portátiles; la japonesa un monumento a Manco Cápac que tuvo su ubicación luego en el distrito de La Victoria; y la china una fuente de bronce existente hoy en el Parque de la Exposición. Los granaderos argentinos, cuyos vistosos uniformes constituyeron una de las grandes atracciones en los desfiles, entregaron sus caballos y sus lanzas al ejército del Perú ${ }^{47}$.

La grandilocuencia del éxito de la república ha sido un aspecto central en la conmemoración del centenario. El gobierno de Leguía consciente del ambiente marcado por el derrotismo, el fracaso y escisión del Perú como consecuencia de la guerra con Chile ${ }^{48}$, hizo de la conmemoración del centenario un instrumento político para realzar su gobierno. La inauguración de obras en una década hizo que el bicentenario fuera reiterado en las ceremonias de entrega, como las Av. Leguía (hoy Arequipa), Progreso (ahora Venezuela), Mariátegui (hoy Colonial), el Museo de Arqueología, Hospital Loayza, Hospital del Niño, entre otras. Como afirma Juan Orrego, el centenario fue un momento propicio para «proyectar una imagen de orden y progreso al interior y exterior del país», y la

\footnotetext{
46 J. C. Mariátegui, Lo nacional y exótico (Lima: Biblioteca Amauta, 1988), 40.

47 J. Basadre, Historia de la República del Perú [1822-1933], tomo 14 (Lima: Producciones Cantabria, 2014), 68.

${ }^{48}$ De hecho, en la conmemoración del centenario, Chile no había sido invitado por el Perú; no solo por tener problemas limítrofes, sino por el nacimiento de discurso de odio hacia los enemigos chilenos, lo que en el siglo XX será uno de los componentes de la identidad construida en contraposición de enemigos externos.
} 
conmemoración perdió su significado por «estar ligadas a la figura de Leguía» ${ }^{49}$. Así, con la conmemoración se silenciaba la situación de posguerra para mostrar cómo el Estado iba por la senda del progreso y la modernización, articulándose con las regiones del interior del Perú (conscripción vial), formando patriotismo (conscripción militar) y la atención de las necesidades del indígena (con la creación de la Dirección de Asuntos Indígenas).

\section{¿Abrazar el desarrollo y soltar el pasado (de la guerra)? Con un paso adentro del bicentenario}

Desde la culminación del conflicto armado interno, CAI (1980-2000), hasta el día de hoy se ha establecido una imperiosa pretensión por los grupos de poder (incluida la mayoría de la prensa nacional) en no perder tiempo en los problemas generados por el paso de la guerra, sino seguir con el paradigma del desarrollo. Lo que dio paso a políticas de impunidad sin el debido proceso de justicia y la postergación de derechos a la reparación de las personas afectadas por el CAI, siendo más una política de compasión que una prioridad del Estado en los últimos 19 años como sociedad de posguerra. Y, ¿el bicentenario tendrá en cuenta el contexto de posguerra o estará signada por la grandilocuencia de la conmemoración representando al Perú en su riqueza y sus aciertos?

El Perú experimentó la violencia más intensa, extendida y prolongada de toda la historia republicana, que tuvo un costo mayor a todas las guerras externas y civiles. El CAI se refiere al periodo protagonizado por grupos alzados en armas (Partido Comunista Peruano Sendero Luminoso el 3 de abril de 1980 y Movimiento Revolucionario Tupac Amaru, MRTA el 4 de noviembre de 1987), las fuerzas armadas y comités populares de defensa dando un saldo de 69.280 víctimas mortales, 15.000 desaparecidos y más de 6.500 sitios de entierros clandestinos registrados por el Informe Final de la Comisión de la Verdad y Reconciliación, IFCVR (2003). Recientemente, en el 2019, la Dirección General de Búsqueda de Personas Desaparecidas actualizó la cifra a 20.511 personas. Por su parte, la Comisión de la Verdad y la Reconciliación «ha determinado que, entre 1980 y el 2000, aproximadamente el $61 \%$ de las víctimas fatales provocadas por los agentes del Estado fueron mediante la desaparición forzada ${ }^{50}$, dicho procedimiento implicaba una selección de víctimas, que consistía en sustraer a un sujeto de la mirada pública y desaparecerlo. En menor medida, Sendero Luminoso, organización que, de manera sincronizada, utiliza «en forma concurrente y masiva el asesinato y la tortura como métodos de la "lucha armada" y utiliza el secuestro como forma de reclutamiento ${ }^{51}$. La violencia no afectó de forma similar ni estuvo dosificada equitativamente según género, ya que, según el grupo etario, «fueron los hombres entre 20 y 49 años quienes conformaron el grueso de las víctimas fatales reportadas a la CVR (más del $55 \%$ ), mientras que las mujeres de todas las edades suman poco menos del $20 \%$ de las víctimas» ${ }^{52}$. Sin embargo, las violaciones sexuales alcanzan cifras exorbitantes hacia las mujeres. Dicha práctica, utilizada por ambas fuerzas, desestructura en primera instancia a la familia, ya que un miembro se encuentra ausente, dando lugar a hondos sufrimientos a los familiares y amigos de la persona desaparecida, acrecienta la duda de su vida, la eterna espera

\footnotetext{
49 J. L. Orrego, «Hacia el bicentenario: ¿cómo conmemorar la independencia?» (ponencia presentada en el Coloquio en homenaje a Franklin Pease: del Tawantinsuyu a la Historia del Perú, Pontifica Universidad Católica del Perú, 11 al 13 de noviembre de 2009), 3.

${ }^{50}$ Comisión de la Verdad y Reconciliación, Hatun Willakuy. Versión abreviada del Informe Final de la Comisión de la Verdad y Reconciliación (Perú. Lima: CVR, 2004), 55.

${ }^{51}$ Comisión de la Verdad y Reconciliación, Hatun Willakuy..., 42.

${ }^{52}$ Comisión de la Verdad y Reconciliación, Hatun Willakuy..., 52.
} 
de su regreso y la total incertidumbre de su suerte y paradero. Y los que cargan con el dolor profundo e inefable son sus familiares, que pierden a su conyugue sin poder realizar el duelo. Además, las masacres no toleraban los entierros, de acuerdo con la práctica ritual andina, lo que muestra la prohibición de trasladar los cuerpos a los cementerios quedando en lugares profanos sin marcas ni cruces ${ }^{53}$.

Muchos no pudieron denunciar la desaparición por no tener registros legales que demostraran la existencia de la persona desaparecida, por la destrucción de documentos civiles y religiosos producto de la actuación de las fuerzas del orden y los grupos alzados en armas. La falta de reconocimiento legal de la situación del desaparecido relegaba a un ámbito de incertidumbre jurídica: no tener acta de defunción, no estar inscrito en el Registro Único de Víctimas ${ }^{54}$, no poder reclamar herencias del desaparecido, entre otras. Para miles de personas que viven en comunidades campesinas y amazónicas, el acceso a la justicia les resultó un camino tortuoso de trámites engorrosos y viajes prolongados, se tuvieron que enfrentar a la indiferencia de los funcionarios del Estado, en tierras ajenas que discriminan por idioma, raza, economía e instrucción educativa. Del pino llama peregrinaje político a esta práctica política de líderes campesinos en busca del Gobierno para denunciar los abusos y el abandono en ciudades que contaban con la presencia inconclusa del Estado ${ }^{55}$.

Además, el CAI hace alusión a dos décadas de sufrimiento, de vulneración a los derechos humanos y el respeto a la dignidad humana. Se hizo notorio que la población campesina y pueblos ashánincas habían resistido lo peor de esos años, ya que la IFCVR demuestra que la muerte y la desaparición se distribuyeron según geografía, clase y etnicidad; es decir, pone sobre el tapete las profundas fracturas y diferencias entre las poblaciones quechuas, ashánincas y las poblaciones urbanizadas. Una de las conclusiones del Informe Final de la Comisión de la Verdad y Reconciliación demuestra que la muerte y la desaparición se distribuyeron según geografía, clase y etnicidad. En la mayoría de los casos, las víctimas eran campesinos pobres, con poca conciencia de sus derechos, con un difícil acceso a la justicia, con redes sociales débiles y con escasos contactos urbanos. De las 69.280 víctimas fatales, la población campesina constituye el grueso de las víctimas: «... el $79 \%$ vivía en zonas rurales y el $56 \%$ se ocupaba en actividades agropecuarias» ${ }^{56}$.

La CVR ha podido apreciar que, conjuntamente con las brechas socioeconómicas, el proceso de violencia puso de manifiesto la gravedad de las desigualdades de índole étnico-cultural que aún prevalecen en el país. Del análisis de los testimonios recibidos resulta que el 75 por ciento de las víctimas fatales del conflicto armado interno tenían el quechua u otras lenguas nativas como idioma materno ${ }^{57}$.

${ }^{53}$ F. Reátegui, R. Barrantes y J. Peña, Desapariciones forzadas y derechos de las víctimas: la respuesta humanitaria a las demandas de verdad, justicia y reparación (Lima: IDEHPUCP, Fundación Konrad Adenauer, 2012).

${ }^{54}$ Entidad perteneciente al Consejo de Reparaciones, creada el 2006 para acreditar la afectación de «víctima», requisito indispensable para recibir algún tipo de reparación. La Comisión Multisectorial de Alto Nivel, CMAN, creada en el 2004, es la encargada de implementar las reparaciones de acuerdo con el Plan Integral de Reparaciones, creada bajo la Ley n. ${ }^{\circ} 28592$.

${ }_{55}$ P. del Pino, «Ayacucho: economía y poder en el siglo XIX», Ideología n. 13 (1993).

${ }^{56}$ Comisión de la Verdad y Reconciliación, «Conclusiones generales del Informe Final de la CVR», en Informe Final, tomo VIII (Lima: Comisión de la Verdad y Reconciliación, 2003), 245.

${ }^{57}$ Comisión de la Verdad y Reconciliación, «Conclusiones generales del Informe Final de la CVR», 246. 
A diferencia de otros países de América del Sur (con excepción de Colombia), donde los desaparecidos tienen un rostro urbano, profesional y de clase media; en Perú, el peso étnico, rural, analfabeto y la pobreza conforman el grueso de las víctimas desaparecidas. Las lógicas de la guerra fueron guiadas por el racismo, discriminación y abominación hacia compatriotas, vistos como el «atraso del Perú». Aquellas distancias emocionales, muy vigentes, como refirió Degregori:

Las distancias que hay entre Lima y provincias no son solo físicas, espaciales. Existe una distancia emocional que hace que las diferencias no solo sean paisajísticas, sino jerárquicas: tendencialmente, cuanto más arriba estás geográficamente, más abajo te ubicas socialmente y más periférico en la estructura de sentimientos ${ }^{58}$.

Una clara muestra de que las concepciones sobre el poblador andino/campesino/quechuahablante no habían cambiado son las primeras interpretaciones al fenómeno de la violencia. El caso que más resalta es el del informe de la comisión investigadora $^{59}$, el del asesinato de los 8 periodistas y un guía en Uchuraccay (Ayacucho) el 26 de enero de 1983. En él se entrevé que la masacre fue producto de un malentendido por las diferencias culturales existentes, como señala el informe de Mario Vargas Llosa:

El que haya un país real completamente separado del país oficial es, por supuesto, el gran problema peruano. Que al mismo tiempo vivan en el país hombres que participan del siglo XX y hombres como los comuneros de Uchuraccay y de todas las comunidades iquichanas que viven en el siglo XIX, para no decir en el siglo XVIII. Esa enorme distancia que hay entre los dos Perú está detrás de la tragedia que acabamos de investigar ${ }^{60}$.

La vigencia del pensamiento presentado por Vargas Llosa era y aún es vigente entre diversos sectores de la opinión pública y medios de prensa. La interpretación de los sucesos estaba lejos de entender a los campesinos con agencia política y social, ya que «los campesinos habían buscado (re)presentarse como "gente ignorante", ajenos al mundo moderno, al castellano y a la tecnología de la cámara fotográfica ${ }^{61}$. Sorprende que aún en la actualidad las percepciones sobre el campesino, marcadas por racismo, discriminación e inferioridad, sean extendidas en el Perú.

La voluntad de olvido y pasar las páginas son discursos muy presentes y promocionados por los grupos políticos que tienen responsabilidades con la guerra interna. Hacen el uso manoseado de la verdad, el mandato de hacer memoria (conveniente) para «terruquear» al adversario, sea político de izquierda, campesino que protesta por el ingreso de concesiones en su tierra, nativo amazónico que defiende el ambiente, joven que reclama derechos educativos, mujeres que denuncian al Estado patriarcal. Todavía más en este imaginario social, se extiende para nombrar a los que actualmente se oponen a las mineras

\footnotetext{
${ }^{58}$ C.I., Degregori, Heridas abiertas, derechos esquivos. Derechos humanos, memoria y Comisión de la Verdad y Reconciliación. Obras escogidas IX. (Lima: IEP, 2015), 185.

${ }^{59}$ La comisión estaba presidida por Mario Vargas Llosa acompañado por tres antropólogos, un jurista y dos lingüistas, que estuvieron un solo día en Uchuraccay para recoger sus versiones mediante una audiencia pública el 12 de febrero de 1983.

${ }^{60}$ Mario Vargas Llosa (1983) en C. I., Degregori, Qué difícil es ser Dios. El Partido Comunista del PerúSendero Luminoso y el Conflicto Armado Interno en el Perú: 1980-1999 (Lima: IEP, 2011), 48.

${ }^{61}$ P. del Pino, «Ayacucho: economía y poder en el siglo XIX», Ideología n. ${ }^{\circ} 13$ (1993), 60.
} 
considerándoles como «terroristas antimineros» ${ }^{62}$ o el caso de los amazónicos de Bagua considerados por la prensa y Alan García como «salvajes opuestos al desarrollo» ${ }^{63}$. Se fuerza la reconciliación o se promueve la reconciliación sin contenido ni ética, sino como mero instrumento de la política. Por ejemplo, que se haya dado el indulto al presidente Alberto Fujimori (el 24 de diciembre del 2017, siendo anulado el 03 de octubre del 2018) y que se haya llamado el 2018 como el «año del diálogo y la reconciliación nacional» solo por ese acto político es una clara muestra de cómo no se entiende el dolor ajeno.

Qué esperar del bicentenario, si a 16 años de la entrega del IFCVR, la mayoría de las políticas de reparación y búsqueda de personas desaparecidas han sido incorporadas más por la presión de las mismas organizaciones e instituciones de derechos humanos, mostrando su dolor a un sector indiferente. Su actuar ha estado marcado por:

...el acto político de «caminar a la puerta del Estado» (Estadu punkunman puriraniku) para presentar denuncias de desaparición da cuenta de una ciudadanía que transita espacios dominados por la «lectoescritura», con predominancia de funcionarios discriminadores de «saco y corbata» (apu runa hina). Un gobierno del que no se sienten parte, pero se ven obligadas a ingresar al sistema a fin de ser escuchadas, reconocidas como mujeres víctimas que cargan el dolor y hacen llamado a la compasión. Su búsqueda de Estado, acompañado de testimonios centrados en el desaparecido, con fotografías y símbolos (banderola y la cruz «no matar») se convierten en caja de resonancia para interpelar al público peruano ${ }^{64}$.

Esta politicidad da cuenta de que la resistencia y agencia de la población quechua en exigir reformas en políticas de reparación está cargada de una historicidad de luchas por reconocimiento y dignificación. De esta manera, el trabajo articulado con instituciones de defensa de los derechos humanos y las movilizaciones de organizaciones de afectados lograron el reconocimiento de la doble afectación, la priorización de la reparación para adultos mayores, la transferencia del derecho a la educación, la ley de búsqueda de personas desaparecidas y la creación del Banco Nacional de Datos Genéticos.

Empero, la exigencia de los derechos humanos desencadena otros dramas de dolor relacionados al maltrato por su condición étnica en instituciones públicas. El racismo, discriminación y desprecio son regularidades constantes dentro de la sociedad peruana que interconectadas con la postergación de los derechos humanos ocasionan dolores mayores. Las luchas por la memoria también encaran «... a la sociedad y los funcionarios por su indiferencia e indolencia ante tanto dolor creciente» ${ }^{65}$. Desde el Gobierno Regional de Ayacucho, los intentos por construir un lugar de memoria han sido muy vagos. Ni las políticas de reparación han sido asumidas dentro de los instrumentos de gestión como el Plan de Desarrollo Concertado y el Plan Bicentenario 2024. Lo que impide la asignación de presupuesto para el expediente técnico hasta el 2021 de acuerdo con el Plan Multianual de Inversiones. Los funcionarios públicos se encuentran poco sensibilizados sobre la importancia de La Hoyada y su constante remoción. En el mismo Plan Bicentenario, el Perú

\footnotetext{
${ }^{62}$ R. Silva. Mujeres y conflictos ecoterritoriales. Impactos, estrategias, resistencias (Lima: AIETI, DEMUS, Flora Tristan, CNDDHH, 2018).

${ }^{63}$ Ó. Espinoza de Rivero, «¿Guerreros o salvajes? Los usos políticos de la imagen de los indígenas amazónicos en el espacio público mediático», en Imaginación visual y cultura en el Perú, ed. por G. Cánepa (Lima: Fondo Editorial de la Pontificia Universidad Católica del Perú, 2011), 247-262.

64 J. Ramos López, «Poner (o materializar) al desaparecido en La Hoyada, Santuario de la memoria», Revista Peruana de Antropología 6 (2020), 129.

${ }^{65}$ López, «Poner (o materializar) al desaparecido en La Hoyada, Santuario de la memoria», 129.
} 
hacia el 2021 (2011), en su eje estratégico de derechos fundamentales y dignidad de personas, no se contempla políticas de reparación ni políticas de memoria para la construcción de una sociedad con bienestar para todos y todas. Lo que confluye en una memoria negacionista que abraza el desarrollo y suelta su pasado ${ }^{66}$.

Más aún en un contexto donde las decisiones políticas generan puntos de quiebre en el campo de la memoria responsable como es el caso de la Hoyada, Santuario de la memoria. Un lugar de horror donde militares produjeron ejecuciones extrajudiciales y cremaron cuerpos para anular la posibilidad de identificarlos. $Y$ tras luchas constantes de organizaciones de afectados y de derechos humanos se ha logrado convertir en un lugar de reflexión y de dignificación. Pero ahora quieren destinar una parte de este lugar para la ampliación del aeropuerto de Ayacucho. Estos intentos deshonran la memoria de los desaparecidos, niegan el dolor de sus familiares y es una clara muestra de cómo los derechos humanos son postergados por decisiones revestidas de desarrollo.

La conmemoración de los doscientos años de independencia del Perú se impone en el correr de los días mediante agendas culturales, académicas, festivas, construcción de obras, exposiciones fotográficas, conferencias y pocas actividades críticas ${ }^{67}$ hasta el día de hoy. La Comisión Nacional del Bicentenario ha empezado a desplegar su trabajo de conmemoración bajo el lema «el país que imaginamos». En Ayacucho, por ejemplo, ya se viene gestionando la construcción del «Parque Cultural Bicentenario», que será de una extensión de tres mil metros cuadrados y ubicado en la zona Acuchimay, conocido como el mirador de Ayacucho. Tendrá como objetivo impulsar el turismo regional y como un espacio público con componentes reflexivos sobre la historia republicana.

Además, Martín Vizcarra, presidente del Perú, hizo el lanzamiento de la agenda del bicentenario en Ayacucho el 10 de noviembre de 2018 con el siguiente discurso:

Seis banderas del bicentenario: una, por un país que lucha frontalmente contra la corrupción; dos, por un país que hace del diálogo su principal arma contra la violencia; tres, por un país integrado, moderno y competitivo; cuatro, por un país con igualdad de oportunidades para todos y todas [...]; cinco, por un país sostenible y que es respetuoso de la naturaleza; y seis, [...] por un país orgulloso de su identidad y diversidad. Este proceso de diálogo permanente debe conducirnos a construir el pacto social que el Perú necesita. El bicentenario nos invita a soñar y el país necesita de todos nosotros para hacer realidad esos sueños...68.

Resulta muy sugerente y atractiva la selección de la agenda principal del bicentenario, pues, de resultas, constituye los ideales de un Perú mejor del que tenemos. Esperemos que el componente crítico y reflexivo se haga más visible porque se corre el riesgo de caer en la grandilocuencia de la conmemoración. Es muy importante pensar el bicentenario desde la producción de sujetos nacionales, es decir, cómo el Estado nación ha afianzado a personas como el ideal de sujetos nacionales y los ha extendido a la diversidad de las poblaciones para que alcancen la talla establecida; y cuánto ha costado construir sujetos nacionales en los 200 años de vida republicana.

\footnotetext{
${ }^{66}$ J. Ramos López, «Los caminos tortuosos de las defensoras de la(s) memoria(s) de la posguerra peruana», Revista PH 96, Instituto Andaluz de Patrimonio Histórico, n. ${ }^{\circ} 96$ (2019), 251-254, doi: https://doi.org/10.33349/2019.96.4339

${ }^{67}$ El concurso nacional «Murales de la Libertad: el País que Imaginamos», en noviembre del 2019 y la «Feria Bicentenario».

${ }^{68}$ Recolección propia.
} 
Por ello, ver a las comunidades rurales como sociedades posguerra implica tener en cuenta la modificación de las estructuras y relaciones de poder a causa de la guerra interna; la pervivencia de odios, rencores, venganzas y miedos entre ellos. Más aún cuando el vecinofamiliar-autoridad está comprometido con la desaparición del familiar. Son escenarios donde «el que recuerda» (yuyaq) sufre porque convive con «quien hizo desaparecer» (chinkachik); «el que busca» (maskaq) es motivado más por la reparación económica que por la memoria, justicia, o viceversa. Realidades regidas por el miedo a los problemas del narcotráfico, las que son vistas como la continuación de la guerra. Y también es ver al Perú como sociedad de posguerra para enfrentar la deuda moral que tenemos no solo como un mecanismo de sentirnos «éticamente responsables», sino de construir un futuro saludable y de bienestar.

\section{¿200 años de construir peruanos? Reflexiones finales}

A doscientos años de producir sujetos nacionales mediante políticas de ordenamiento, homogeneización y modernización bajo los idearios nacionales resulta urgente reflexionar lo violento y deshumanizador que ha significado para diversos grupos en situación de vulnerabilidad. Como hemos demostrado en el presente escrito, la posguerra ha sido un momento clave para transformar la realidad, pero lejos de ella se han pospuesto las demandas de los grupos desfavorecidos. Tanto en el proceso de la independencia, la guerra con Chile y la violencia política interna han sido escenarios que han negado la agencia de poblaciones marginadas en sus derechos y su capacidad de producir historia. Esta trama negacionista se materializó en la manera pomposa y festiva de la conmemoración de las metafechas de la independencia, en especial en el centenario donde se puso énfasis en los proyectos de civilización. Así, festejar la mantención del Estado peruano, la que se erigió a base de desigualdades, prejuicios, discriminación y racismo, que a doscientos años fue progresivamente construyendo la igualdad ante la ley. Pero en la práctica es expresada en formas más sofisticadas y sutiles que aún continúan operando el andamiaje de desprecio, racismo que tienen origen en el orden colonial y con legitimación desde la posindependencia.

Entonces, la forma en cómo se estructura el Estado peruano moderno abre más las brechas de desigualdad entre sujetos nacionales (a imagen de los grupos de poder) y sujetos a quienes se les cuestiona su ciudadanía por no cumplir con los idearios nacionales, quienes son pensados como portadores de lo peligroso, del atraso y lo salvaje. En conclusión, las conmemoraciones del acto fundacional del Estado peruano en las metafechas de la independencia han marginado y simplificado hasta silenciar el contexto de posguerra, como un momento para repensar las prácticas desiguales del ejercicio del poder y fundar un nuevo orden igualitario. Al contrario, el uso instrumental de la posguerra ha servido para generar explicaciones donde la diversidad cultural constituye el principal factor para el atraso del país y su escisión. En esa línea, las conmemoraciones del centenario han enaltecido los proyectos políticos de modernización sin reflexionar la forma violenta en cómo se construían sujetos nacionales mediante las instituciones estatales, como la educación y el servicio militar. El bicentenario apunta en la misma línea al estar desprovista de la reflexión crítica respecto a las desigualdades persistentes que además silencia la condición de sociedad de posguerra.

Nos queda mucho por construir, esperemos que el bicentenario no sea visto solo como un momento festivo de fechas, sino también como un proceso de un sentido histórico y de reflexión profunda. Más que honrar a la historia construida, desde y para los grupos privilegiados, de qué y cómo recordar el pasado, el bicentenario debe constituir una oportunidad para reflexionar desde múltiples perspectivas y proponer caminos de 
articulación mediante los sentidos identitarios con la finalidad de superar la «imagen nacional» construida históricamente en base a desigualdades, racismo y discriminación.

\section{Referencias}

Althusser, L. «Ideología y aparatos ideológicos del Estado». En Ideología, un mapa de la cuestión, S. Zizek, 115-167. México: Fondo Cultura Económica, 2008.

Anderson, B. Comunidades imaginadas. Reflexiones sobre el origen y la difusión del nacionalismo. México D. F.: Fondo de Cultura Económica, 1993.

Arendt, H. Sobre la violencia. Madrid: Alianza Editorial, 2005.

Basadre, J. Historia de la República del Perú [1822-1933], tomo 14. Lima: Producciones Cantabria, 2014.

Bonilla, H. «El problema nacional y colonial del Perú en el contexto de la Guerra del Pacífico». En Un siglo a la deriva, H. Bonilla. Lima: IEP, 1980. . Guano y Burguesía en el Perú. Lima: IEP, 1984.

. El futuro del pasado. Las coordenadas de la configuración de los Andes, tomo II. Lima: Fondo Editorial del Pedagógico de San Marcos, 2005.

Braudel, F. La larga duración en la historia y las ciencias sociales. Madrid: Alianza, 1979.

Centro Nacional de Planeamiento Estratégico. Plan bicentenario, el Perú hacia el 2021. Lima: CEPLAN, 2011.

Comisión de la Verdad y Reconciliación. «Conclusiones generales del Informe Final de la CVR». En Informe Final, tomo VIII, 245-266. Lima: Comisión de la Verdad y Reconciliación, 2003.

. Hatun Willakuy. Versión abreviada del Informe Final de la Comisión de la Verdad y Reconciliación. Perú. Lima: CVR, 2004.

De Robayo, M. V., O. I. Acosta y A. Santamaría. Las historias de un grito: doscientos años de ser colombianos. Exposición conmemorativa del bicentenario. Bogotá: Museo Nacional de Colombia, 2010.

Degregori, C. I. Qué difícil es ser Dios. El Partido Comunista del Perú-Sendero Luminoso y el Conflicto Armado Interno en el Perú: 1980-1999. Lima: IEP, 2011.

. Heridas abiertas, derechos esquivos. Derechos humanos, memoria y Comisión de la Verdad y Reconciliación. Obras escogidas IX. Lima: IEP, 2015.

Del Pino, P. «Huamanga en la guerra con Chile. 1879-1884». Informe de investigación para optar el grado de bachiller. Universidad Nacional San Cristóbal de Huamanga, Ayacucho, 1990. 
. «Ayacucho: economía y poder en el siglo XIX». Ideología n. 13 (1993).

Espinoza de Rivero, Ó. «¿Guerreros o salvajes? Los usos políticos de la imagen de los indígenas amazónicos en el espacio público mediático». En Imaginación visual y cultura en el Perú, editado por G. Cánepa, 247-262. Lima: Fondo Editorial de la Pontificia Universidad Católica del Perú, 2011.

González, M. Horas de lucha. Lima, 1972.

Guerrero, J., L. Wiesner y F. Martínez (comps.). Memoria, historia y nación. A propósito del bicentenario de la independencia de Latinoamérica. Medellín: La Carreta Editores, 2010.

Hernández, D. «Actos de la nación. Conmemoración, identidad y representación: análisis del Bicentenario mexicano». Pacarina del Sur 8, n. ${ }^{\circ} 30$ (2017).

Husson, P. De la guerra a la rebelión. (Huanta, siglo XIX). Lima: Instituto Francés de Estudios Andinos, 1992.

Jelin, E. Las conmemoraciones: Las disputas en las fechas «in-felices». Madrid y Buenos Aires: Siglo XXI Editores, 2002.

Junca, $\mathrm{H}$. «Al museo no le sirve de nada tener colecciones fantásticas si nadie la visita». Revista Arcadia n. 68 (2011), 14-15.

Kersffeld, D. «Entre evocaciones y desmemorias: México ante su propio Bicentenario». En La revolución en el bicentenario. Reflexiones sobre la emancipación, clases y grupos subalternos, coordinado por B. Rajland y M. C. Cotarelo, 115-131. Buenos Aires: CLACSO, 2009.

Klaren, P. Nación y sociedad en la historia del Perú. Lima: IEP, 2005.

Lynch, J. The Spanish-American Revolutions, 1808-1826. Nueva York: Norton, 1973.

Manrique, N. Las guerrillas indígenas en la guerra con Chile: campesinado y nación. Lima: Centro de Investigación y Capacitación, 1981.

Mariátegui, J. C. Lo nacional y exótico. Lima: Biblioteca Amauta, 1988.

. Siete ensayos de interpretación de la realidad peruana. Lima: Biblioteca Amauta, 1995.

Mc Evoy, C. «De la mano con Dios. El nacionalismo católico y la guerra del Pacífico, 18791881». Revista de Historia de Chile y América 5, n. ${ }^{\circ} 1$ (2004), 83-136.

Méndez, C. Incas sí, indios no: apuntes para el estudio del nacionalismo criollo en el Perú, $2^{\mathrm{a}}$ ed. Lima: IEP (n. ${ }^{\circ}$ 56, Serie Historia 10), 2000. 
- «Tradiciones liberales en los Andes o la ciudadanía por las armas: campesinos y militares en la formación del Estado peruano». En La mirada esquiva. reflexiones históricas sobre la interacción del Estado y la ciudadanía en los Andes (Bolivia, Ecuador y Perú), editado por M. Irurozqui, 125-153. Madrid: Consejo Superior de Investigaciones Científicas, 2005.

. «Militares Populistas. Ejército, etnicidad y ciudadanía en el Perú». En Repensando la subalternidad. Miradas críticas desde/sobre América Latina, compilado por P. Sandoval, 561-598. Lima: IEP, SEPHIS, 2009.

. La república plebeya. Huanta y la formación del Estado peruano, 1820-1850. Lima: IEP, 2014.

Nora, P. Les Lieux de memoire. Montevideo: Trilce, 2008.

Orrego, J. L. «Hacia el bicentenario: ¿cómo conmemorar la independencia?». Ponencia presentada en el Coloquio en homenaje a Franklin Pease: del Tawantinsuyu a la Historia del Perú. Pontifica Universidad Católica del Perú. 11 al 13 de noviembre de 2009.

Ramos López, J. «Los caminos tortuosos de las defensoras de la(s) memoria(s) de la posguerra peruana». Revista PH 96, Instituto Andaluz de Patrimonio Histórico, n. ${ }^{\circ} 96$ (2019), 251-254. doi: https://doi.org/10.33349/2019.96.4339

. «Poner (o materializar) al desaparecido en La Hoyada, Santuario de la memoria». Revista Peruana de Antropología 6 (2020), 129.

Reátegui, F., R. Barrantes y J. Peña. Desapariciones forzadas y derechos de las víctimas: la respuesta humanitaria a las demandas de verdad, justicia y reparación. Lima: IDEHPUCP, Fundación Konrad Adenauer, 2012.

Remy, M. I. «Los discursos sobre la violencia en los Andes. Algunas reflexiones a propósito de chiaraje». En Poder y violencia en los Andes, editado por E. Urbano y M. Lawer, 261-276). Cusco: Centro de Estudios Regionales Andinos Bartolomé de las Casas, 1991.

Rueda, R. «El 20 de julio de 1810. Un episodio de protesta urbana en Bogotá». Memoria y Sociedad 11, n. 23 (2007): 117-135.

Sala i Vila, N. Selva y Andes. Ayacucho (1780-1929). Historia de una región en la encrucijada. Madrid: Consejo Superior de Investigaciones Científicas, 2001.

Silva, R. Mujeres y conflictos ecoterritoriales. Impactos, estrategias, resistencias. Lima: AIETI, DEMUS, Flora Tristan, CNDDHH, 2018.

Thurner, M. Republicanos andinos. Lima: IEP; CBC, 2006. 
Vargas, S. «200 años de construir colombianos». Memoria y Sociedad 14, n. o 29 (2010): 147150.

. «El bicentenario de la independencia en Colombia: rituales, documentos, reflexiones». Memoria y Sociedad 15, n. 31 (2011): 66-84.

Vega, R. «Amargo bicentenario de la independencia en Colombia, ¿cuál independencia?» Casa de las Américas, n. 260 (2010): 147-171.

Zapata, A., N. Pereyra y R. Rojas. Historia y cultura de Ayacucho. Lima: IEP, UNICEF, 2008. 